\title{
Editorial
}

\section{Photovoltaic Materials and Devices 2014}

\author{
Bhushan Sopori, ${ }^{1}$ Peter Rupnowski, ${ }^{1}$ Sudhakar Shet, ${ }^{2}$ and Prakash Basnyat ${ }^{1}$ \\ ${ }^{1}$ National Renewable Energy Laboratory, National Center for Photovoltaics, 15013 Denver West Parkway, Golden, CO 80401, USA \\ ${ }^{2}$ New Jersey Institute of Technology, Department of Materials Science and Engineering, 138 Warren Street, University Heights, Newark, \\ NJ 07102, USA \\ Correspondence should be addressed to Bhushan Sopori; bhushan.sopori@nrel.gov
}

Received 14 October 2014; Accepted 14 October 2014; Published 22 December 2014

Copyright (C) 2014 Bhushan Sopori et al. This is an open access article distributed under the Creative Commons Attribution License, which permits unrestricted use, distribution, and reproduction in any medium, provided the original work is properly cited.

Ever increasing demand on the energy has fostered many new generation technologies, which include photovoltaics. In recent years, photovoltaic industry has grown very rapidly. The installed capacity of PV for 2013 was about $37 \mathrm{GW}$ and 2014 sales are expected to be around $45 \mathrm{GW}$. However, there has been excess production for last several years, which is responsible in part for the low prices (about $60 \$ / \mathrm{W}$ ). To lower the PV energy costs further, a major strategy appears to be going to high efficiency solar cells. This approach is favored (over lower cost/lower efficiency) because cell efficiency has a very large influence on the acceptable manufacturing cost of a PV module. Hence, the PV industry is moving toward developing processes and equipment to manufacture solar cells that can yield efficiencies $>20 \%$. Thus, further research is needed within existing technologies to accomplish these objectives. Likewise, research will continue to seek new materials and devices.

This is the third special issue of International Journal of Photoenergy on Photovoltaic Materials and Devices and is aimed at selection of papers on recent advances in materials and PV systems. This issue contains thirteen papers on various aspects of photovoltaics. These fall into four broad categories:

(1) advances in conventional solar cells and materials based on microcrystalline $\mathrm{Si}$, modeling of bandgaptailored CIGS, and characterization and process modeling of new materials and device designs;

(2) design and applications of grid connected arrays and applications to building integration: of particular importance in concentrator application is the effect of nonuniform illumination;
(3) novel materials: fullerene-based OPV and improvements in preparation of dye sensitized solar cells;

(4) investigations on cuprous oxide, $\mathrm{MoTe}_{2}, \mathrm{Cu}_{1.4} \mathrm{Te}$, and CZTS by sol-gel method.

We hope that readers enjoy this issue.

\section{Acknowledgment}

Special thanks are due to Dr. Takwa Maged for his continued help in coordinating this issue.

Bhushan Sopori

Peter Rupnowski

Sudhakar Shet

Prakash Basnyat 

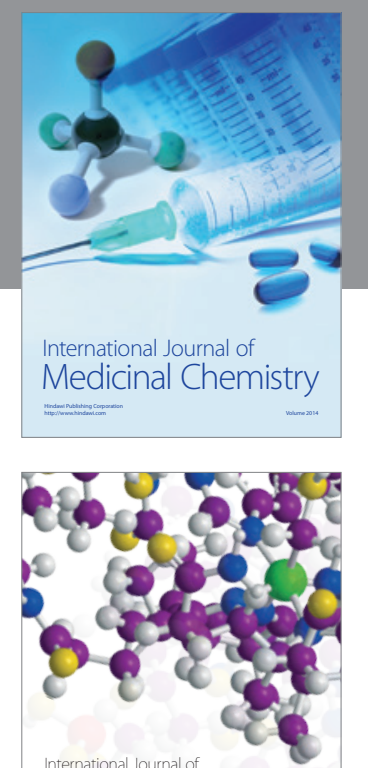

\section{Carbohydrate} Chemistry

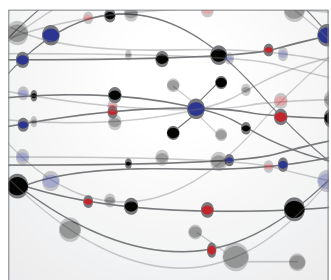

The Scientific World Journal
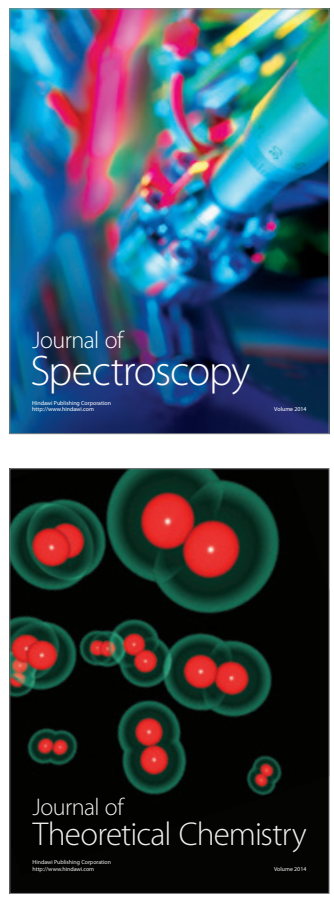
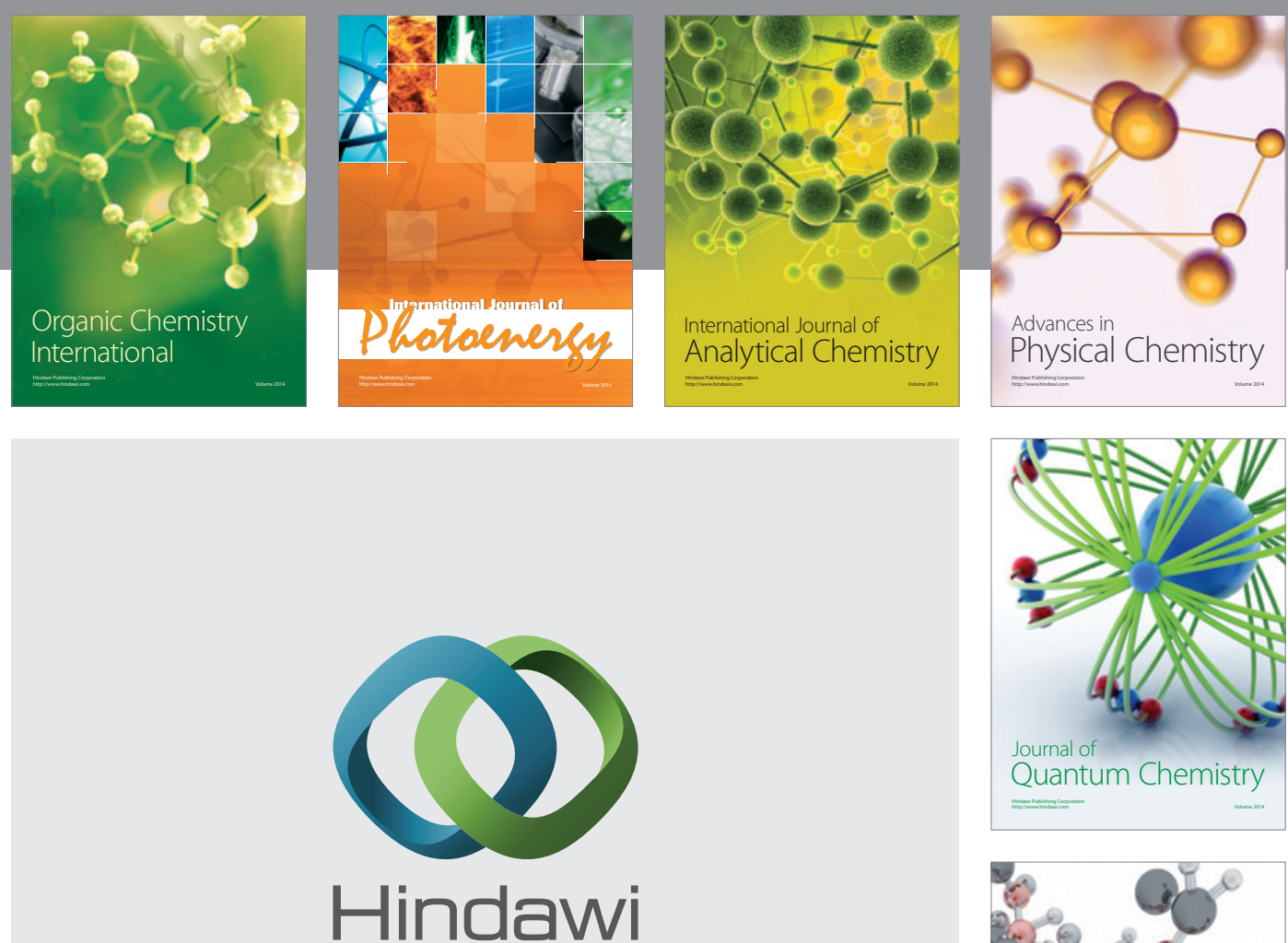

Submit your manuscripts at

http://www.hindawi.com

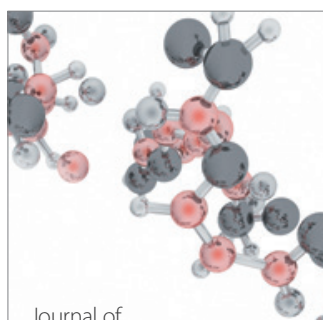

Analytical Methods

in Chemistry

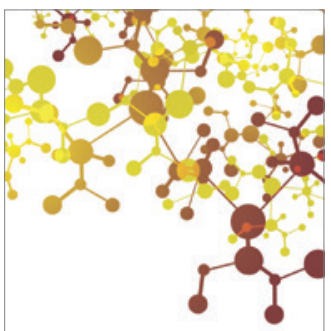

Journal of

Applied Chemistry

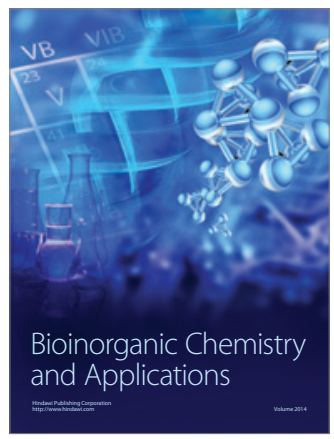

Inorganic Chemistry
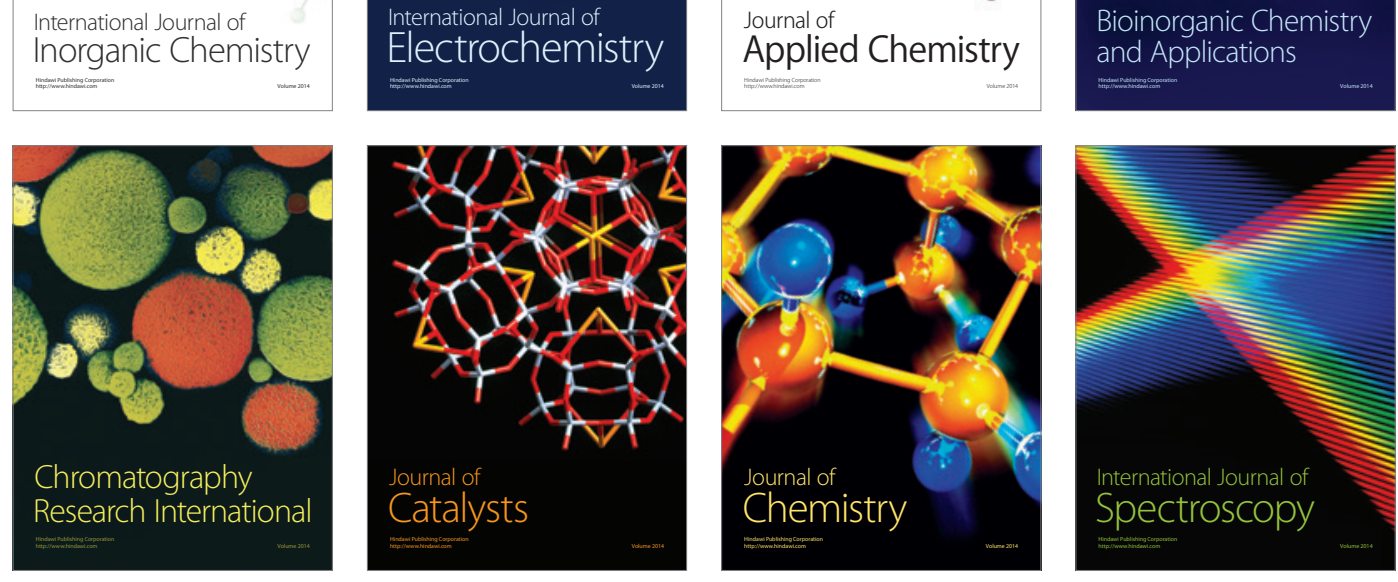